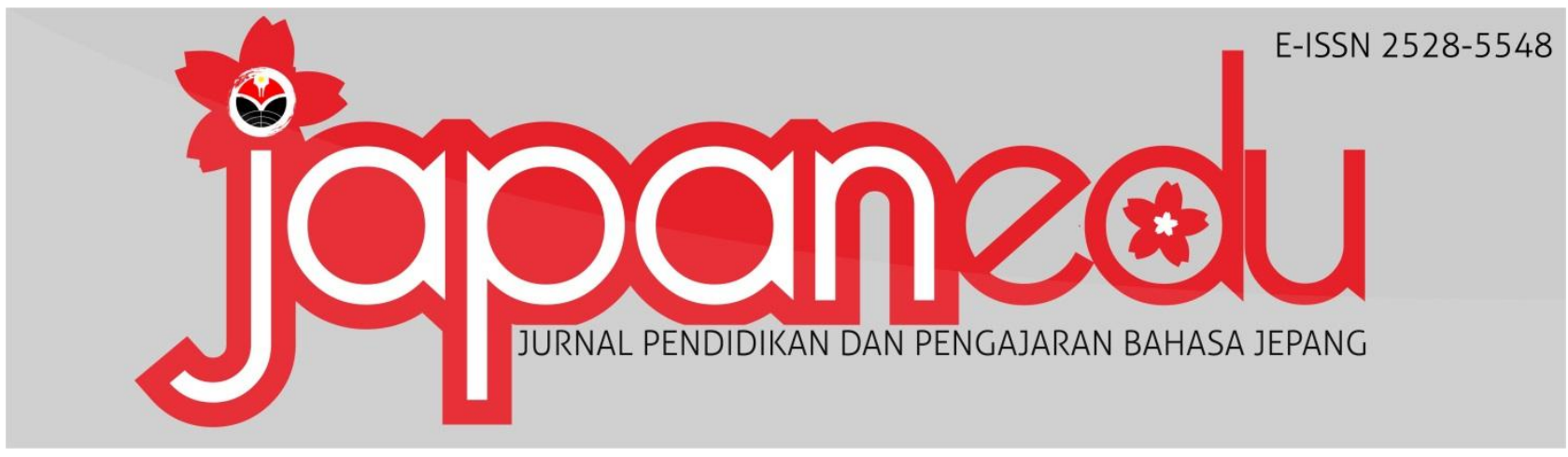

\title{
EFEKTIVITAS PENGGUNAAN KARTU IDENTITAS BAHASA JEPANG TERHADAP PENGUASAAN PERCAKAPAN SEDERHANA PADA SISWA SMA
}

Robby Putra Prakoso, Neneng Sutjiati , Ahmad Dahidi

\author{
${ }^{1}$ Departemen Pendidikan Bahasa Jepang, Universitas Pendidikan Indonesia, Jl. Dr. \\ Setiabudhi No. 229, Bandung 40154, Indonesia
}

\author{
E-mail: bryantshinoda@yahoo.co.jp \\ Telp: +62 812-9124-5142
}

\begin{abstract}
Abstrak. Kemampuan berbicara merupakan hal penting bagi pembelajar bahasa Jepang. Masalah yang sering ditemukan pada siswa dalam pembelajaran keterampilan berbicara bahasa Jepang yaitu di antaranya siswa sering kali merasa bingung dan tidak percaya diri untuk berbicara bahasa Jepang. Hal ini dikarenakan kurangnya latihan pada keterampilan berbicara. Berdasarkan latar belakang di atas, peneliti melaksanakan penelitian mengenai efektivitas penggunaan kartu identitas bahasa Jepang terhadap kemampuan berbicara siswa. Tujuan penelitian ini adalah untuk mengetahui efektivitas penggunaan media kartu identitas terhadap kemampuan berbicara bahasa Jepang. Selain itu, tujuan penelitian ini adalah untuk mengetahui tanggapan siswa mengenai media kartu identitas. Penelitian ini merupakan penelitian kuantitatif dengan menggunakan metode eksperimen kuasi dan dengan desain penelitian one group pretest-post-test design. Instrumen yang digunakan berupa tes lisan dan angket. Sampel yang digunakan adalah siswa XI IPS SMAN 2 Bandung tahun ajaran 2015/2016 sebanyak 20 orang. Hasil analisis data menunjukkan perolehan nilai rata-rata siswa sebelum diterapkannya media kartu identitas yaitu sebesar 12,95 dan setelah diterapkannya media kartu identitas meningkat menjadi 23,8. Berdasarkan perhitungan statistik komparasional didapatkan hasil $\mathrm{t}_{\text {hitung }}$ sebesar 29,73 dan $\mathrm{t}_{\text {tabel }}$ pada taraf signifikansi 5\% adalah 2,09 dan taraf signifikansi $1 \%$ adalah 2,86, ini berarti $t_{\text {hitung }}>t_{\text {tabel }}$, maka Hk diterima dan Ho ditolak. Sehingga dapat diinterpretasikan bahwa terdapat perbedaan yang signifikan antara keterampilan berbicara bahasa Jepang siswa sebelum dan sesudah diterapkannya media kartu identitas. Kemudian, berdasarkan hasil analisis data angket, sebagian besar siswa memberikan respons positif terhadap media kartu identitas untuk meningkatkan keterampilan berbicara bahasa Jepang.
\end{abstract}

Kata kunci: efektivitas; keterampilan berbicara bahasa Jepang; kartu identitas

Abstract. Speaking competency is important for Japanese language learners. Problems cited by the students in learning the Japanese language speaking skills are among the students often feel confused and insecure to speak Japanese. This is due to lack of exercise on speaking skills. Based on the above background, the researchers conducted research on the effectiveness of the use of identity cards Japanese against their speaking ability. The purpose of this study was to examine the effectiveness of media use identity cards to the ability to speak Japanese. Moreover, the purpose of this study was to determine the response of the media student identity card. This research is a quantitative research using quasiexperimental methods and research design one group pre-test-post-test design. Instruments used in the form of an oral test and a questionnaire. The samples used were students XI IPS SMAN 2 Bandung 
2015/2016 school year as many as 20 people. The result showed the acquisition value of the average student prior to the implementation of the identity card media that is equal to 12.95 and the introduction of an identity card media increased to 23.8. Based on statistical calculation results obtained komparasional thitung 29.73 and ttable at significance level of $5 \%$ was 2.09 and $1 \%$ significance level was 2.86 , this means thitung> ttabel, then Hk Ho accepted and rejected. So that it can be interpreted that there are significant differences between Japanese speaking skills of students before and after the implementation of media identification card. Then, based on data analysis questionnaires, most students give positive response to the media the identity card to improve his skills speak Japanese.

Keywords: efectivity, Japanese speaking ability, identity card

\section{Pendahuluan}

Belajar merupakan hal yang tiada batasnya, terutama belajar untuk memperoleh bahasa kedua. Pemerolehan bahasa kedua tidak sama dengan pemerolehan bahasa pertama, karena menurut Tarigan (1988, hlm. 84) "pemerolehan bahasa pertama (PB1) memang bersifat "primer" paling sedikit dalam dua hal: dari segi urutan (memang yang pertama) dan dari segi kegunaan (hampir dipakai selama hidup)." Sedangkan pemerolehan bahasa kedua mengacu kepada mengajar dan belajar bahasa kedua atau bahasa asing. Suatu proses belajar mengajar tentunya melibatkan beberapa komponen yaitu pelajar, pengajar, media, metode dan lain-lain.

Ruhimat dkk (2012, hlm. 217) mengatakan bahwa ciri utama dari kegiatan pembelajaran adalah adanya interaksi. Interaksi yang terjadi antara pelajar dengan lingkungan belajarnya, baik itu dengan guru, teman- temannya, tutor, media pembelajaran, dan / sumber belajar lainnya. Sedangkan ciri-ciri lainnya dari pembelajaran ini berkaitan dengan komponen- komponen pembelajaran itu sendiri. Dimana di dalam pembelajaran akan terdapat komponen- komponen sebagai berikut: tujuan, materi/ bahan ajar, metode dan media, evaluasi, anak didik/ siswa dan adanya pendidik/ guru.

Banyak bahasa asing yang diajarkan di Indonesia dan salah satunya adalah bahasa Jepang. Hal pertama yang harus dipelajari siswa dalam mempelajari bahasa Jepang tentu saja adalah mempelajari huruf hiragana dan katakana yang biasa disebut huruf kana. Akan tetapi juga, di dalam pengajaran bahasa Jepang pada dasarnya siswa diajarkan dan diarahkan untuk dapat menggunakan bahasa tersebut dengan baik dan benar. Baik untuk berinteraksi secara langsung maupun tidak langsung dengan orang yang ada di sekelilingnya yang samasama dapat menggunakan bahasa Jepang. Dengan interaksi tersebut siswa berkomunikasi untuk menyatakan keinginan serta pendapatnya melalui bahasa yang baik dan benar. Terlebih lagi dengan adanya kurikulum terbaru, ini berarti melalui pengajaran bahasa diharapkan siswa dapat terampil dalam berbahasa.

Dalam mempelajari bahasa, ada empat keterampilan berbahasa yang harus dikuasai oleh pembelajar tersebut, yaitu keterampilan menyimak, keterampilan berbicara, keterampilan membaca, dan keterampilan menulis. Sehingga dapat dipahami bahwa mempelajari bahasa kedua itu tidak mudah dikarenakan pembelajar harus mempelajari keempat aspek tersebut. Hal ini merupakan penyebab siswa banyak mengalami kesulitan dalam memahami materi. Penguasaan kosakata diduga menjadi salah satu faktor yang dapat mempengaruhi dalam memahami materi pembelajaran. Masalah yang sering dihadapi oleh siswa adalah bagaimana caranya agar ia dapat mengatasi rasa malu untuk berbicara di depan umum serta kurangnya rasa percaya diri.

Kurangnya ragam media dalam pembelajaran, merupakan salah satu penghambat dalam perkembangan pembelajaran siswa. Dikarenakan media 
yang monoton, maka siswa sudah dapat memahami apa yang harus dilakukan tanpa diperintahkan oleh pengajar, dan justru terkadang mengabaikannya dikarenakan siswa merasa bosan. Dengan mengadakan beberapa media lain merupakan salah satu upaya untuk mengatasi hal tersebut. Dari berbagai macam media yang ada, penulis mencoba menerapkan dengan menggunakan kartu identitas sebagai medianya.

Berdasarkan uraian di atas, maka penulis merumuskan masalah sebagai berikut:

a. Bagaimana hasil belajar siswa sebelum menggunakan media kartu identitas?

b. Bagaimana efektivitas penggunaan media kartu identitas dalam pembelajaran percakapan di SMAN 2 Bandung?

c. Bagaimana respon siswa terhadap pembelajaran percakapan menggunakan media kartu identitas?

\section{Metode Penelitian}

Penelitian ini menggunakan metode eksperimen quasi atau eksperimen semu, yang tidak membutuhkan kelas kontrol atau kelas pembanding. Penelitian jenis ini merupakan penyempurnaan dari jenis praeksperimen dan berusaha untuk memenuhi kriteria penelitian yang mempunyai validitas tinggi. Dalam penelitian jenis ini peneliti mencoba memenuhi kriteria eksperimen dengan mengadakan tes awal dan tes akhir untuk mengukur perolehan dari perlakuan uji dan sudah mempunyai kelompok kontrol. Peneliti dapat menggunakan kelompok eksperimen sebagai "kelompok kontrol" sehingga kedua kelompok tersebut merupakan objek yang sama. Karena penentuan subjek penelitian tidak dilaksanakan secara acak, jenis penelitian semacam ini dikelompokkan ke dalam eksperimen semu (Setiyadi, 2006, hlm. 135-136).

Data adalah bahan mentah yang perlu diolah sehingga menghasilkan informasi atau keterangan, baik kualitatif maupun kuantitatif yang menunjukan fakta (Riduwan, 2012, hlm. 5). Data penelitian adalah sejumlah informasi penting yang diperlukan untuk menjawab masalah penelitian melalui prosedur pengolahannya (Sutedi, 2011, hlm. 155). Menurut Riduwan (2012, hlm. 32) mengatakan bahwa data merupakan bahan penting yang akan dimanfaatkan untuk : menjawab permasalahan, mencari apa saja yang digunakan untuk mencapai tujuan penelitian, sebagai bukti pencarian fakta, dan membuktikan hipotesis penelitian. Sehingga dapat diketahui bahwa data merupakan hal yang sangat penting untuk mengetahui hal apa saja yang ingin peneliti ketahui, sehingga data yang dipergunakan harus sesuai dengan permasalahan dan tujuan penelitian.

Untuk memperoleh data membutuhkan alat pengumpul data (instrumen), secara garis besar instrumen terbagi menjadi dua yakni berupa tes dan non tes. Dalam penelitian ini instrumen yang digunakan dua macam tes yakni Pretest dan Posttest, dan non tes berupa angket.

Penelitian ini mengambil data yang hasilnya berupa skor angka, sehingga penelitian ini termasuk ke dalam penelitian kuantitatif. Sutedi (2011, hlm. 23) menjelaskan bahwa penelitian kuantitatif adalah penelitian yang datanya berupa angka-angka yang diolah dengan menggunakan metode statistik. Dasar penelitian kuantitatif adalah filosofi positivisme yang menekankan bahwa setiap fenomena bersifat tetap, berdimensi tunggal dan fragmental, sehingga dianggap tidak akan mengalami perubahan ketika 
penelitian sedang berlangsung. Sehingga pengolahan datanya sebagai berikut :

a) Menentukan skor tes awal (Pre test) dan skor tes akhir (Post Test)

b) Mencari Mean variabel (x) dan variabel (y)

1) Mencari nilai mean (rata-rata) pre test $\mathrm{O}_{1}$ :

$$
M x=\frac{\Sigma x}{N}
$$

Keterangan :

$\mathrm{Mx}=$ nilai rata-rata pretest

$\sum \mathrm{x}=$ jumlah total nilai pretest

$\mathrm{N}=$ jumlah peserta pretest

2) Mencari nilai mean (rata-rata) post test $\mathrm{O}_{2}$ :

$$
\mathrm{My}=\frac{\sum \mathrm{Y}}{\mathrm{N}}
$$

Keterangan :

My = nilai rata-rata posttest

$\sum \mathrm{Y}=$ jumlah total nilai posttest

$\mathrm{N}=$ jumlah peserta posttest

c) Mencari nilai rata-rata selisih hasil pre test dan post test

$$
\mathrm{Md}=\frac{\sum \mathrm{d}}{\mathrm{N}}
$$

Keterangan :

Md = nilai rata-rata selisih antara posttest dan pre-test

$\sum \mathrm{d}=$ jumlah nilai selisih antara post-test dan post-test

$\mathrm{N}=$ jumlah siswa

(Sutedi, 2011, hlm.218) d) Menghitung derajat kebebasan

Rumus :

$$
\mathrm{db}=\mathrm{n}-1
$$

Keterangan :

$\mathrm{db}=$ nilai derajat kebebasan

$\mathrm{n}=$ jumlah siswa

e) $\frac{M d}{\sqrt{\frac{\sum X^{2} d}{n(n-1)}}}$ Mencari t hitung

$$
\mathrm{t}=
$$

Keterangan :

$\mathrm{t}=$ nilai $\mathrm{t}$ yang dihitung

Md = nilai rata-rata selisih antara post test dan pre test

$\sum \mathrm{d}^{2}=$ jumlah kuadrat devisi

$\mathrm{n}=$ jumlah siswa

f) Interpretasi dengan melihat tabel

g) Untuk menghitung data angket akan diolah dengan rumus (Supardi, 2006, hlm. 20)

$$
P=\frac{f}{n} X 100 \%
$$

Keterangan :

$\mathrm{P}=$ Presentase

$\mathrm{f}=$ Frekuensi

$\mathrm{n}=$ Jumlah koresponden

Temuan dan Pembahasan

Menghitung rata-rata hasil Pre-test dan

Post-test

$$
M x=\frac{259}{20}
$$




$$
\begin{aligned}
& =12.95 \\
\text { My } & =\frac{476}{20} \\
& =23.8
\end{aligned}
$$

Mencari gain (d)

Mencari nilai rata-rata gain $(\mathrm{d})$

$\mathrm{M}_{\mathrm{d}}=$

$$
\begin{aligned}
& =\frac{217}{20} \\
& =10.85
\end{aligned}
$$

\section{Menghitung nilai kuadrat deviasi}

Sebelum menghitung nilai kuadrat deviasi, kita perlu mencari pengkuadratkan dari gain $\left(\mathrm{d}^{2}\right)$. Berikut hasil pengkuadratan dari gain (d).

$$
\begin{aligned}
\sum x^{2} d & =\sum d^{2}-\frac{\left(\sum d\right)^{2}}{N} \\
& =2405-\frac{(217)^{2}}{\frac{20}{47089}} \\
& =2405-\frac{20}{\frac{24}{24}} \\
& =2405-2354.45 \\
& =50.55
\end{aligned}
$$

Mencari nilai $t$ hitung

$$
t_{o}=\frac{10.85}{\sqrt{\frac{50.55}{\sqrt{20(20-1)}}}}
$$

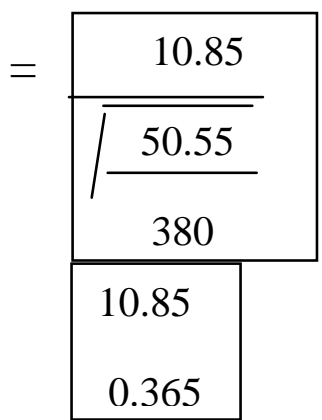

$=$

$=29.73$

\section{Memberikan}

interpretasi (tafsiran)

Untuk

menginterpretasikan hasil penelitian, digunakan dua hipotesis yaitu:

1. Hipotesis kerja (Hk): terdapat hasil yang signifikan dari penggunaan media kartu identitas terhadap kemampuan percakapan apabila nilai $t$ hitung $>$ t tabel.

2. Hipotesis nol (Ho): tidak terdapat hasil yang signifikan dari penggunaan media kartu identitas terhadap kemampuan percakapan apabila nilai $t$ hitung $<$ t tabel.

\section{Menguji kebenarannya dengan \\ membandingkan nilai $t$ hitung dengan nilai $t$ tabel}

Untuk

menguji kebenaran hipotesis dengan membandingkan nilai $t$ hitung dengan nilai $t$ tabel, perlu dicari terlebih dahulu derajat kebebasan (db) dengan rumus:

$\mathrm{db}=\mathrm{N}-1$

$=20-1$

$=19$

Nilai $t$ tabel untuk db 19 adalah 2.09 pada taraf signifikansi $5 \%$ dan 2.86 pada taraf signifikansi 1\%. Dapat dilihat bahwa nilai $t$ hitung lebih besar dibandingkan dengan nilai $t$ tabel $(t$ hitung $=29.73>t$ tabel $=2.04$ pada taraf signifikansi 
$5 \%$ dan 2.86 pada taraf signifikansi 1\%). Hal ini menunjukkan bahwa $\mathrm{Hk}$ diterima dan Ho ditolak, yang berarti terdapat hasil yang signifikan dari penggunaan media kartu identitas dalam pembelajaran percakapan.

Dengan diterimanya hipotesis kerja, maka dapat dibuktikan bahwa media kartu identitas dapat meningkatkan kemampuan percakapan siswa. Hal ini ditunjukan dengan adanya peningkatan yang cukup signifikan antara hasil pre-test dan post-test seperti yang terdapat pada tabel 4.1 dan tabel 4.2. Peningkatan yang terjadi pada siswa terlihat saat mereka menjawab soal post- test. Yang pada awalnya mereka malu dan ragu dengan jawabannya hingga mereka menjadi lebih percaya diri dan lancar saat menjawab soal. Selain itu dari segi isi, siswa yang awalnya menjawab hanya satu atau dua kata, saat post- test jawaban siswa menjadi lebih siap dalam menjawab. Kemudian dalam penilaian diksi, dapat dikatakan juga siswa mengalami perkembangan. Terlihat dari pemilihan kata, siswa jauh lebih pandai dalam memilih kata yang tepat dan juga bervariasi. Berdasarkan hasil angket yang akan dijelaskan pada subbab selanjutnya, media ini juga dapat meningkatkan motivasi siswa dalam pembelajaran bahasa Jepang.

\section{Kesimpulan}

Pada penelitian ini telah menguji cobakan media kartu identitas dalam pembelajaran bahasa Jepang terhadap kemampuan percakapan sederhana bahasa
Jepang. Pembelajar yang menjadi sampel penelitian, yaitu 20 orang pembelajar bahasa Jepang di kelas XI IPS SMAN 2 Bandung. Dari hasil penelitian, media kartu identitas ini mampu meningkatkan peran siswa dalam proses pembelajaran dan lebih mendominasi dari pada peran pengajar di kelas. Disamping itu juga media ini mampu meningkatkan konsentrasi siswa dalam pembelajaran percakapan bahasa Jepang.

Dengan peran pembelajar yang dominan inilah yang mampu memberikan kesempatan bagi pembelajar untuk lebih banyak berlatih dan mengembangkan keterampilan berbicara bahasa Jepang. Adapun media ini pun dapat menjadi salah satu cara untuk memanfaatkan dan menggunakan bahasa Jepang yang telah dipelajari oleh pembelajar dalam kegiatan percakapan. Siswa juga menjadi lebih percaya diri dan berani untuk melakukan percakapan di depan umum.

Berdasarkan hasil penelitian yang telah dilaksanakan, dapat disimpulkan beberapa hal untuk menjawab rumusan masalah penelitian yang telah dirumuskan sebelumnya:

1. Sebelum diterapkan media kartu identitas pada pembelajaran, siswa kurang begitu lancar dalam melakukan percakapan dan banyak bingung dalam melakukan percakapan.

2. Pembelajaran percakapan dengan menggunakan media kartu identitas efektif digunakan dalam pembelajaran percakapan bahasa Jepang.

3. Penggunaan media kartu identitas dalam pembelajaran percakapan mendapat respon yang sangat baik dan positif. Hal ini karena penggunaan media ini membuat responden lebih nyaman dalam belajar, dan lebih memudahkan untuk mengingat. Selain itu, sebagian besar responden merasa bahwa penggunaan media kartu identitas menyenangkan dan dapat meningkatkan kemampuan responden dalam pembelajaran percakapan sehingga pengunaan media kartu identitas dapat dijadikan alternatif 
Robby Putra Prakoso, Efektivitas Penggunaan Kartu Identitas Bahasa Jepang Terhadap Penguasaan Percakapan Sederhana Pada Siswa SMA

untuk mempelajari percakapan bahasa Jepang.

\section{Pustaka Rujukan}

[1] Riduwan. (2012). Belajar Mudah Penelitian untuk Guru-Karyawan dan Peneliti Pemula. Bandung: Alfabeta.

[2] Ruhimat, Toto. dkk, (2012). Kurikulum dan Pembelajaran. Jakarta: Raja Grafindo Persada.
[3] Setiyadi, Bambang Ag. (2006). Metode Penelitian untuk Pengajaran Bahasa Asing: Pendekatan Kuantitatif dan Kualitatif. Yogyakarta: Graha Ilmu

[4] Sutedi, Dedi. (2011). Penelitian Pendidikan Bahasa Jepang, Bandung: Humaniora.

[5] Tarigan, Guntur H. (1988). Pengajaran Pemerolehan Bahasa. Bandung: Angkasa. 